\title{
Influence of Surface Topographical Interaction between Tool and Material in Micro-Deep Drawing ${ }^{*}$
}

\author{
Tetsuhide SHIMIZU**, Yushiro MURASHIGE**, \\ ${\text { Kuniyoshi } \text { ITO }^{* * *} \text { and Ken-ichi MANABE** }}^{* *}$ \\ ** Department of Mechanical Engineering, Tokyo Metropolitan University, \\ 1-1, Minamiosawa, Hachioji-shi, Tokyo, 192-0397, Japan \\ E-mail: simizu-tetuhide@ed.tmu.ac.jp \\ ${ }^{* * \star S e k i ~ C o r p o r a t i o n, ~ 2-9-22 ~ M y o j i n-c h o H a c h i o j i-s h i, ~ T o k y o, ~ 192-0046, ~ J a p a n ~}$
}

\begin{abstract}
In the miniaturization of dimensions for sheet metal forming, the relative ratio of the surface asperities of tools and blanks to the outside dimensions becomes larger than that in the case of the conventional macroscale process. This means that the surface asperities may affect frictional behavior, so that it would also affect processing characteristics and accuracy of products. In this report, micro-deep drawing for producing cups of $700 \mu \mathrm{m}$ diameter and $20 \mu \mathrm{m}$ thickness is conducted using microtools and stainless steel foils with different surface conditions. To evaluate the effects of surface properties on micro-formability and micro-forming accuracy, punch force, surface accuracy, and the thickness strain distribution of microcups are experimentally investigated. Additionally, using a finite element (FE) model that considers surface roughness, the effect of surface roughness on formability is analyzed under different tool and material surface conditions. Results show that the global forming behavior in microforming is subjected much more intensely to tribological contact behavior, which is caused by the difference of surface asperities, than that in the case of the macroscale region. Moreover, it is shown that predominant factor over this local tribological behavior is the interaction of both tool/material surface asperities that depends on the normal load condition.
\end{abstract}

Key words: Microforming, Surface Asperities, Interfacial Behavior, Micro-Deep Drawing, Foil, Surface Roughness Model

\section{Introduction}

Against the trend toward more and more products having higher and higher electronic content, microforming technology has been receiving much attention as one of the most economical mass production methods for sub-millimeter-scale microcomponents (1). Although the production method has gradually changed from chip-making technology to microforming technology at manufacturing sites, no fundamental knowledge and technological data on their fabrication have been accumulated, and great reliance is still placed on skilled labor. Therefore, to realize further high-precision forming technology, systematizing such technology by an academic approach is indispensable ${ }^{(2)}$.

Over the last decade, many basic research studies of the microforming field were performed worldwide, which mainly revealed the size effects of the material structure and

*Received 1 Sep., 2008 (No. 08-0643) [DOI: 10.1299/jmmp.3.397] 
tribological behavior in the microforming ${ }^{(3)-(9)}$. In step with the success of these basic research studies, the resulting knowledge and experience are coming up to be applied to establish design manuals and codes for tools, dies and blank materials for the industry.

One of the most important process factors in micro-metal forming related to tool/material design is the interfacial behavior between the tool and the material. Particularly in the microscale region, it is preferred not to use a lubricant from the standpoint of not only environmental load but also releasability from tools, lubricant clogging, and the effects of meniscus and viscous forces on formability. Under dry-friction condition, since friction force depends on real contact area and the shear strength of asperity contact during sliding ${ }^{(10)}$, the predominant factor over the frictional behavior between the tool and the material is the contact behavior of surface asperities.

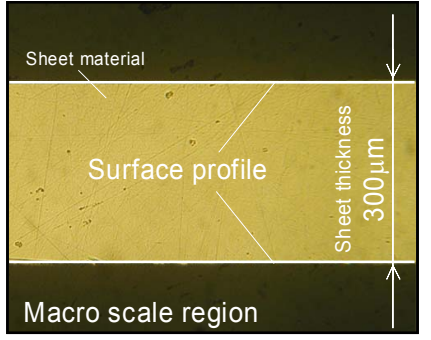

(a) Macroscale region (Thickness $=300 \mu \mathrm{m})$

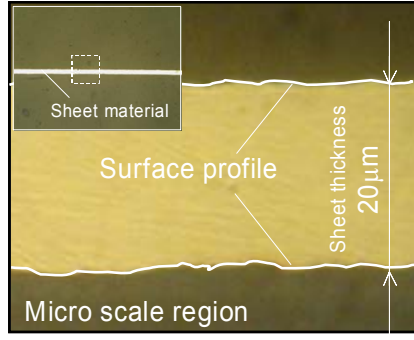

(b) Microscale region (Thickness $=20 \mu \mathrm{m}$ )

Fig. 1 Comparison of cross-sectional images of macro- and micro-sheet materials

In the miniaturization of the dimensions for sheet metal forming, the relative ratio of the surface asperities of tools and blanks to the outer dimensions become larger than that in the case of the conventional macroscale process. Figure 1 shows an example of the comparison of the relative ratio of the surface asperities to sheet thickness between macroand micro- scale sheet materials (C5191-H phosphor bronze). Although the absolute values of surface roughness are nearly close $\left(\mathrm{R}_{\mathrm{z}}=0.8 \mu \mathrm{m}\right)$ in both scales, there is a big difference in the relative ratios to the sheet thickness. This means that surface asperity may largely affect frictional behavior, so that it would also affect the processing characteristics and accuracy of products.

Within the above background, we focused on the surface topography of tool and blank materials in the micro-deep drawing and aimed to clarify the effects of surface asperities of tool/material on microforming characteristics from the viewpoint of the design of tools and materials.

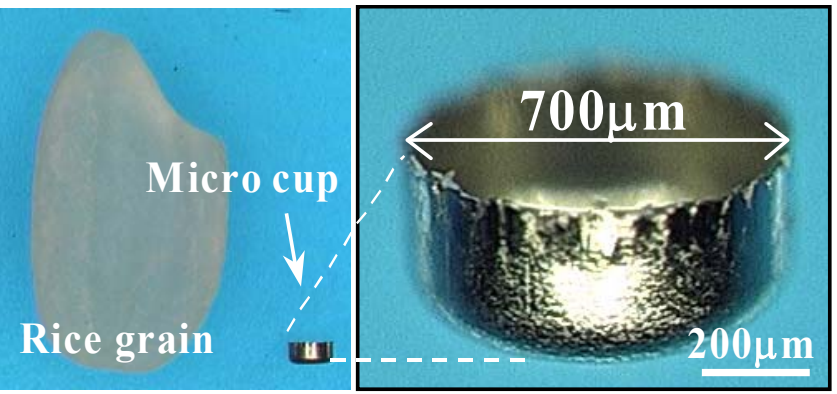

Fig. 2 Appearance of microcup produced in experiment

In this report, micro-deep drawing for producing cups of $700 \mu \mathrm{m}$ diameter and $20 \mu \mathrm{m}$ thickness (Fig. 2) was conducted using three different tools and two different materials, which have different surface properties manufactured by ion beam irradiation and air-blasting treatment. To evaluate the effects of surface properties on microformability and microforming accuracy, punch force, surface accuracy, and the thickness distribution of 
microcups were experimentally investigated. Additionally, using the FE model that considers surface roughness, which was validated in our last report ${ }^{(11)}$, the effects of surface roughness on formability was analyzed under different tool/material surface conditions. Compared with experimental data, the effects of the interaction of surface asperity between the tool and the material on frictional behavior and the global forming behavior in microforming were investigated.

\section{Experiment}

\subsection{Materials}

The material used was a stainless steel (JIS; SUS304-H) ultrathin foil of $23 \mu \mathrm{m}$ average thickness. Aside from the as-received foil material with rolling marks, air-blasting treatment was conducted to make blank specimens with different surface asperities. As a condition of air-blasting treatment, glass powder of 53-63 $\mu \mathrm{m}$ size was irradiated for $30 \mathrm{~s}$ on both sides of the foil. Figure 3 shows the surface images of the as-received blank and air-blasted blank of SUS304-H foil, which were obtained by confocal laser scanning microscopy. As shown in Fig. 3, rolling marks were removed by air-blasting and surface asperities induced by glass powder irradiation was observed. To eliminate the effect of work hardening on the surface because of the air-blasting treatment, both foils of different surface asperities were annealed (Ar gas, $800^{\circ} \mathrm{C}, 1 \mathrm{~h}$ ) after air-blasting treatment.

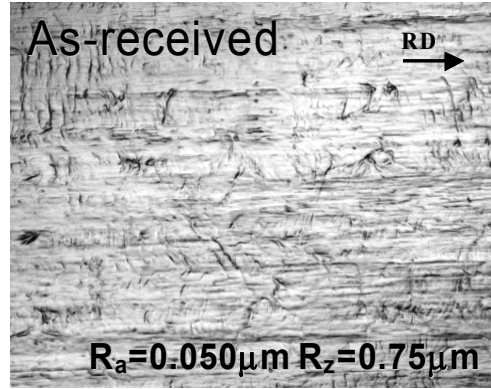

(a) As-received

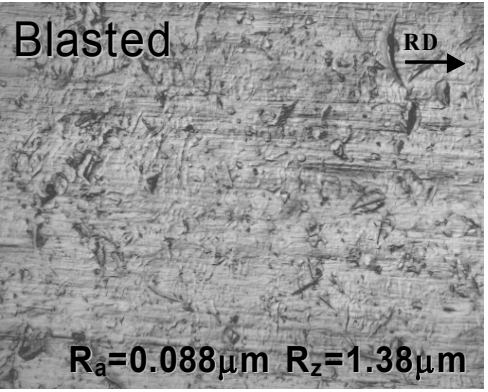

(b) After air-blasting

Fig. 3 Surface images of blank material

\subsection{Experimental setup}

The micro-deep-drawing experiment was performed with a developed blanking-drawing tool set, which we reported in our previous paper ${ }^{(11)}$. For use as a press machine, a miniature precision press machine of desktop size was developed by Seki Corporation. The miniature press machine system is shown in Fig. 4. The press is actuated by a servomotor and it is possible to supply materials progressively using this press.
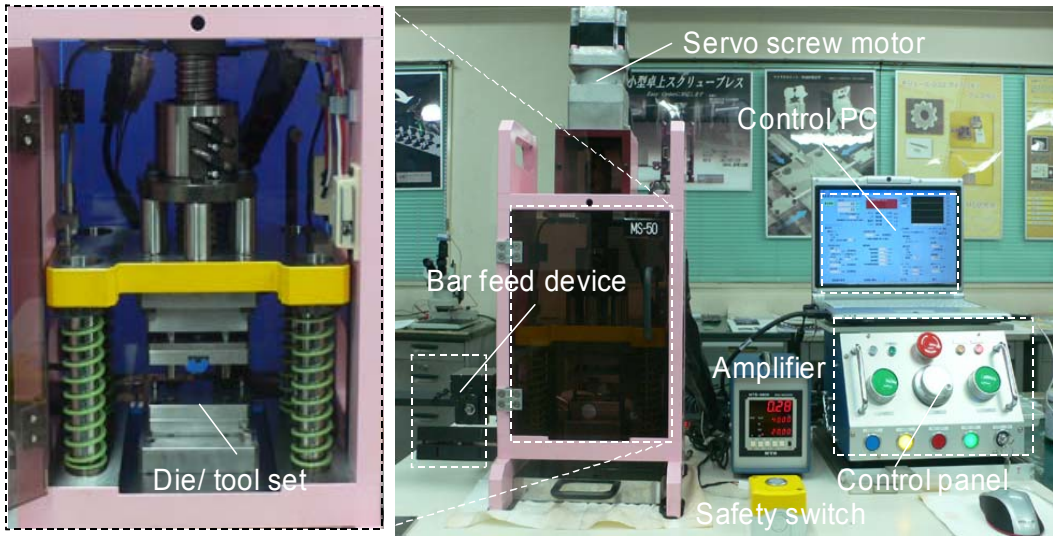

Fig. 4 Appearance of miniature precision press machine system 
Aimed at producing cups of $700 \mu \mathrm{m}$ diameter and 1.6 drawing ratio, a microtool set was designed. Figure 5 shows the appearance of the designed blanking punch-drawing die and drawing punch. Table 1 lists the dimensions of the microtool set used. All microtools were made of sintered WC-Co hard alloy (JIS: V20 tungsten-carbide-cobalt alloy). To fabricate microtools of different surface asperities, in addition to the air-blasting treatment, ion beam irradiation treatment, which is said to be effective for lapping microtool surface finish ${ }^{(12)}$, was conducted. For the air-blasting treatment, glass powder of 53-63 $\mu \mathrm{m}$ size was air-blasted for $5-10 \mathrm{~min}$ on the microtool surface and a rough surface was obtained. The ion irradiation was performed under the conditions shown in Table 2.

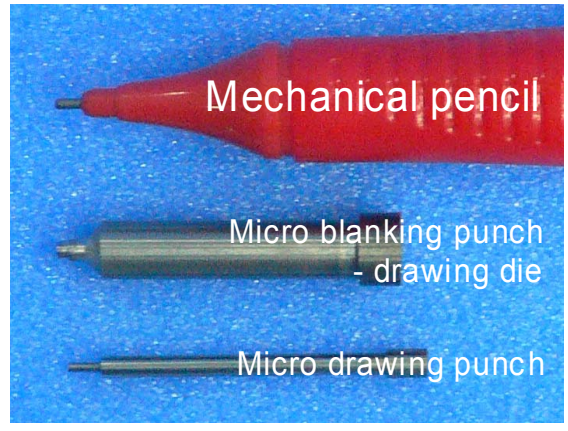

Fig. 5 Microtools for micro-blanking-drawing process

Table 1 Dimensions of microdrawing tools

\begin{tabular}{c|l|c}
\hline Tool & \multicolumn{1}{|c|}{ Measured Item } & Dimension \\
\hline \hline Blanking die & Die diameter & $1.1 \mathrm{~mm}$ \\
\hline \multirow{2}{*}{$\begin{array}{c}\text { Blanking punch- } \\
\text { Drawing die }\end{array}$} & Blanking punch diameter & $1.1 \mathrm{~mm}$ \\
\cline { 2 - 3 } & Drawing die diameter & $0.69 \mathrm{~mm}$ \\
\cline { 2 - 3 } & Die corner radius & $0.1 \mathrm{~mm}$ \\
\hline \multirow{2}{*}{ Drawing punch } & Punch diameter & $0.654 \mathrm{~mm}$ \\
\cline { 2 - 3 } & Punch corner radius & $0.1 \mathrm{~mm}$ \\
\hline
\end{tabular}

Table 2 Conditions for ion beam irradiation

\begin{tabular}{c|c|c|c|c|c}
\hline Ion gas & Acceleration & Vacuum & $\begin{array}{c}\text { Ion current } \\
\text { density }\end{array}$ & $\begin{array}{c}\text { Irraditation } \\
\text { time }\end{array}$ & $\begin{array}{c}\text { Irradiation } \\
\text { angle }\end{array}$ \\
\hline \hline $\mathrm{Ar}$ & $800 \mathrm{eV}$ & $1 \times 10^{-4} \mathrm{~Pa}$ & $1.2 \mathrm{~mA} / \mathrm{cm}^{2}$ & $5-10 \mathrm{~min}$ & $45^{\circ}$ \\
\hline
\end{tabular}
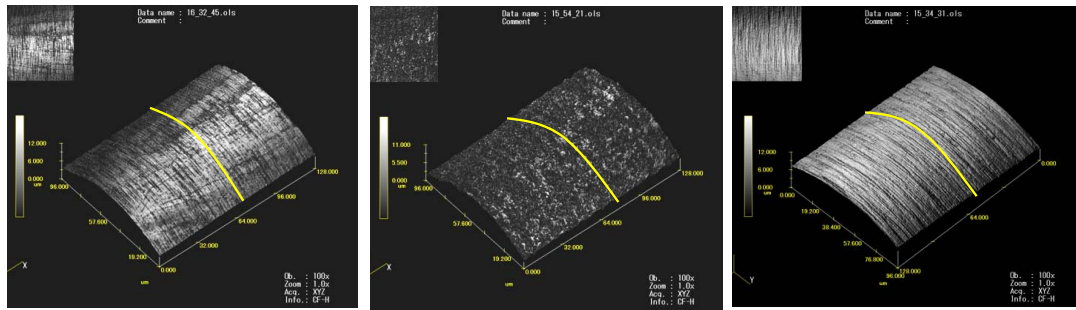

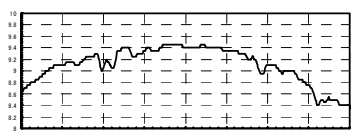

$\mathrm{R}_{\mathrm{a}}=0.15 \mu \mathrm{m} \mathrm{R} \mathrm{R}_{\mathrm{z}}=2.16 \mu \mathrm{m}$ (Standard deviation $\sigma=0.30 \mu \mathrm{m}$ )

(a) Untreated

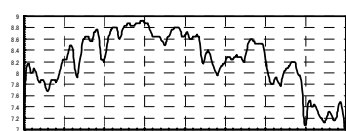

$\mathrm{R}_{\mathrm{a}}=0.45 \mu \mathrm{m} \quad \mathrm{R}_{\mathrm{z}}=3.32 \mu \mathrm{m}$ (Standard deviation $\sigma=0.60 \mu \mathrm{m}$ )

(b) Air-blasted

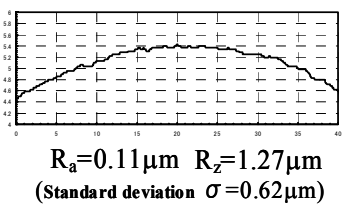

(c) Ion irradiated

Fig. 6 3D Surface images of microdrawing die and punch with different surface characteristics 
Figure 6 shows 3D surface images and surface profile data of the untreated, air-blasted and ion-irradiated micro-drawing punch obtained by confocal laser scanning microscopy. For the untreated tools, there are machined traces on the circumferential direction of the punch surface. On the other hand, for the air-blasted tools, the maximum height of surface roughness was the largest and the dispersion in roughness was also large. Furthermore, for the ion-irradiated tools, although machining marks were slightly observed, the peaks of the asperities were removed by ion sputtering and became relatively smoother with no directional property.

\subsection{Experimental procedure}

By using the above blank material, experimental equipment and tool set, micro-deep-drawing experiments were conducted under a nonlubricated condition. The drawing speed was $0.4 \mathrm{~mm} / \mathrm{s}$ and no blank holder force was applied for better reproducibility, so that the constant gap between the drawing die and the blank holder was always $30 \mu \mathrm{m}$.

To evaluate the formability under each surface condition, punch force was measured with a micro-load cell aligned with the force direction under the microdrawing punch. Additionally, to evaluate the drawn microcup, the cup surface roughness and thickness strain distribution were measured by digital microscopy and confocal laser scanning microscopy.

\section{Experimental results}

\subsection{Effect of tool surface property}

To investigate the effect of tool surface property on microdrawability, punch force was measured during the process. Figure 7 shows comparative data of punch load-stroke curves between the three tools of different surface asperities. As the shape of the curve shows, it has two peaks of maximum value. The first peak of the curve indicates the drawing force and the second peak is caused by ironing. For the drawing force, the air-blasted tool demonstrated the maximum load, and other two tools demonstrated the minimum load. On the other hand, for the ironing force, the maximum load was demonstrated under the condition with the ion-irradiated tool. The ironing force is generally dependent not only on

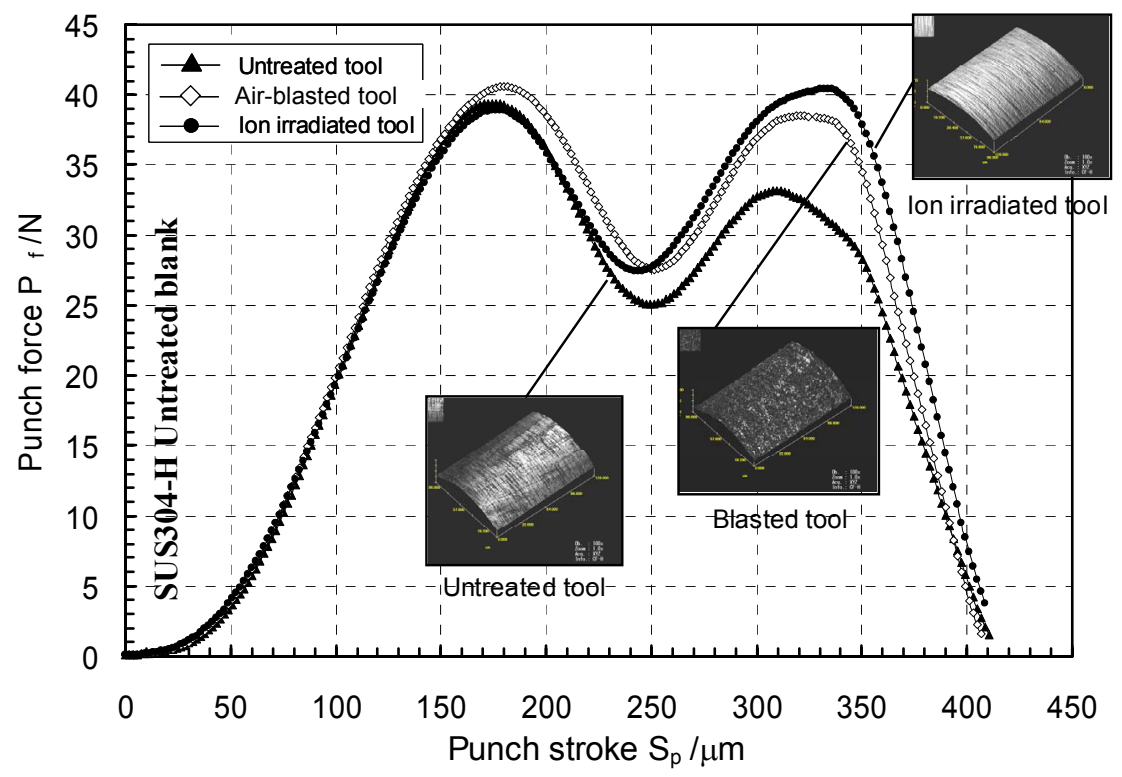

Fig. 7 Load-stroke curves of micro-deep drawing for comparing different surface topographies of tools 
the tribological conditions, but also on the tool clearance between the drawing die and the drawing punch. Hence, tool geometries after the surface treatment were measured to confirm the effect of die clearance. As a result, it was found that the clearance of the ion-irradiated tool became approximately $2 \mu \mathrm{m}$ larger than that of the untreated tool and the air-blasted tool, because of the surface treatment. In other words, the ion-irradiated tool demonstrated the highest ironing value, although it should be have the lowest force because of its large clearance. This means that the difference in load-stroke curve shown in Fig. 7 is a result of the difference in tribological conditions caused by a difference in surface property.

To investigate contact behavior, which brings the difference in tribological conditions, the surface property of microcup after drawing was observed. Figure 8 shows the surface images of the top (A) and bottom (B) sides of the microcup wall of outer surface. As shown in Fig. 8, the surface property of the microcup also has a variance caused by differences in surface property of the tool. In particular, for the microcup drawn by the ion-irradiated tool, scratches and chipping of the material caused by adhesion or sticking to the die were observed. In contrast, for the microcup drawn by the air-blasted tool, although the tool surface has the roughest surface, the surface was smoothened by sliding with the die, and better surface quality was obtained compared with that in the case of the untreated and ion-irradiated tools. Additionally, at the bottom side of the microcup drawn by the untreated tool, a roughened surface similar to an orange peel surface was observed, whereas sliding traces with the die were observed under the conditions with the air-blasted and ion-irradiated tool.
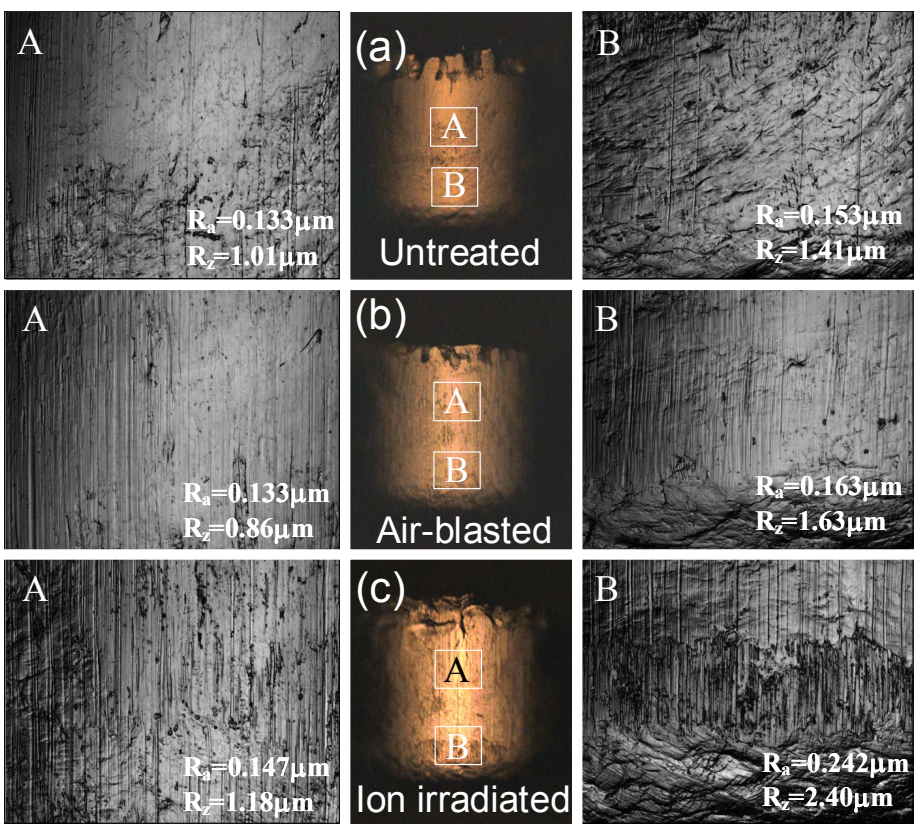

Fig. 8 Surface images of microcup wall drawn using three tools with different surface conditions

In agreement with the load-stroke curve, it was found that the maximum force of the ironing under the condition with the ion-irradiated tool was caused by the strong adhesion between the die and the foil material. Yang et al. reported that by the ion irradiation on WC-Co hard alloy, Co particle, which roles as biding material for WC particle, would sputtered preferentially because of the difference in sputtering rate between $\mathrm{WC}$ and $\mathrm{Co}^{(13)}$. Therefore, it can be considered that WC particles on the surface, which is not fasten strong as bulk material, are easy to induce the adhesion with steel materials because of the chemical compatibility. This means that the chemical composition of the surface is also an important parameter that determines the tribological conditions during the process. 
The thickness strain distributions of the microcups were also measured to investigate the effects of surface asperities on deformation characteristics and forming accuracy, as shown in Fig. 9. Drawn microcups were precisely cut using a dicing saw, which is normally used for cutting semiconductor boards. The data were obtained from cross-section of a half-cut microcup by digital image processing. The thickness strain distributions also indicate different tendencies for different surface property conditions, although there was some dispersion in measurements because of the nonuniformity of the original foil thickness. For the ion-irradiated tool, the thickness distribution tended to be relatively uniform from the cup edge to the cup bottom. On the other hand, for the air-blasted tool, thickness strain decreases locally at the cup corner radius. In contrast, for the untreated tools, thickness strain decreases gradually from the cup corner radius up to the cup bottom.

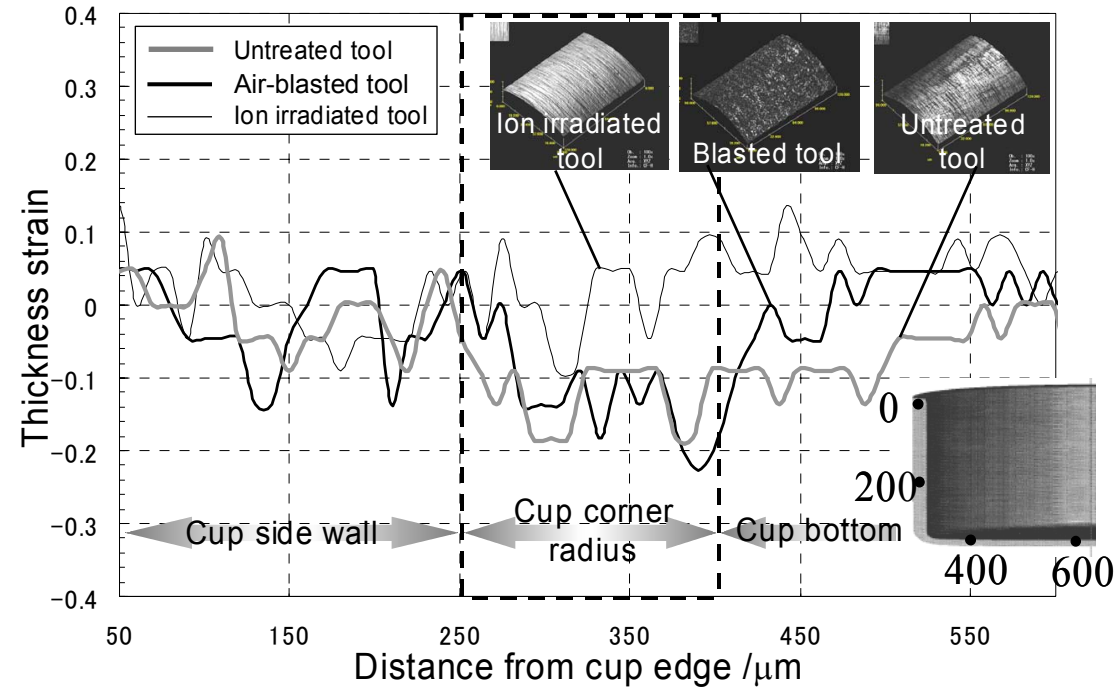

Fig. 9 Thickness strain distribution of microcup drawn using three tools with different surface conditions

Corresponding to the microcup surface images of the untreated-tool condition, it can be considered that because of the thinning of the foil material at the beginning of the process, the thickness became smaller than the tool clearance, and the surface roughening at the bottom side of the cup wall occured. Therefore, it would be quite conceivable that this no-contact situation brought about the minimum ironing force for the untreated-tool condition.

From the results of comparison between different tool processes mentioned above, it was confirmed that tool surface properties largely affect contact behavior, so that they also affect the global deformation behavior of the material in a microscale region. This means that the tool surface properties would markedly affect the formability, surface quality, and forming accuracy of products.

\subsection{Effect of blank surface property}

\subsubsection{Condition for untreated "smooth" tool surface}

Figure 10 (a) shows comparative data of punch load-stroke curves between two foil materials of different surface asperities under the condition with untreated tool. The curves of the air-blasted foil, which has a rough surface, indicate a lower forming force than those of the as-received foil. Particularly in the ironing force, the difference became larger than that in the drawing force.

Since the used tool sets are the same, the difference of the load curve means the difference of frictional behavior between foil and tool in each condition. From the result of 
the untreated tool, it can be considered that the cause of the high ironing force for the as-received foil came from the large contact area, which is caused by a high normal pressure like that in ironing. This means that under condition with the "smooth"-surface tool, the rough surface material would have a lower friction force than the smooth surface material, particularly under a high normal force condition.

\subsubsection{Condition for air-blasted "rough" tool surface}

On the other hand, in the load-stroke curve under condition with the air-blasted tool, although the drawing force was higher than that for the untreated tool (Fig.10 (a)), there is no large difference between the as-received and air-blasted foils, as shown in Fig.10 (b). In contrast to the condition with the smooth tool surface, because the frictional behavior deemed to be much more predominated by the plowing action, it can be considered that the tool surface asperities have a larger influence on frictional behavior under the condition with "rough"-surface tool, so that material surface asperity has minimal effect on frictional behavior.

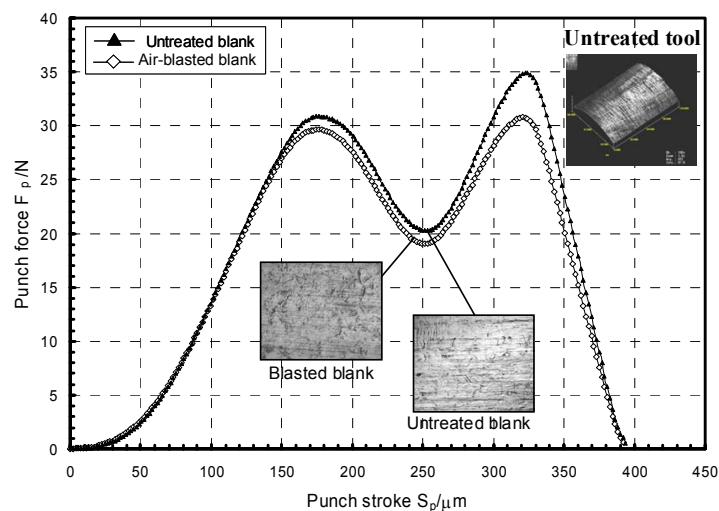

(a) With untreated tool

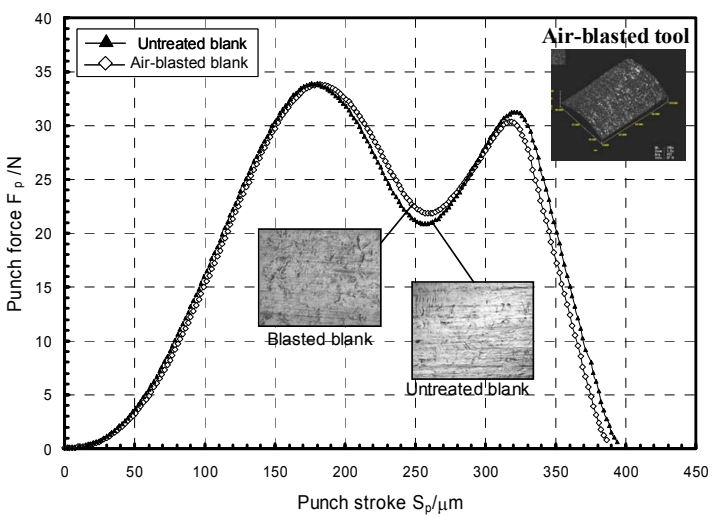

(b) With blasted tool

Fig. 10 Load-stroke curves of micro-deep drawing for comparing different surface topographies of materials

\section{FE analysis}

To discuss local contact phenomena in more detail generally, FE analysis proposed in our last report was carried out.

\subsection{Surface roughness model}

A cyclic triangular concavo-convex configuration was applied to the FE model of micro-deep drawing. Figure 11 shows a schematic view of the surface roughness model. The blank was $1.1 \mathrm{~mm}$ in diameter and $0.02 \mathrm{~mm}$ in thickness. Tool geometries are determined from tool dimensions, which enable the succeessful in fabrication of microcups 
in our previous experiment ${ }^{(11)}$. The axisymmetric FE mesh sizes of quadrilateral four-node elements were $1 \mu \mathrm{m} \times 0.5 \mu \mathrm{m}$. A cyclic surface geometry was modeled as the height of the profile, $\mathrm{R}_{\mathrm{z}}$, and the pitch, $\mathrm{P}$, both of which are variables. This surface model was constructed on whole surface elements of blank and tools. Some of the virtues of what considering the surface asperity in the model are as follows:

1. It is possible to input the geometry of surface asperity as a parameter of the process.

2. It is possible to represent the local deformation of surface asperity caused by contact between the tool and the material.

3. It is possible to investigate the effect of local contact behavior on global deformation properties, like formability and forming accuracy.

Figure 12 shows the distribution of equivalent plastic strain during the process with a surface roughness model. As shown in Fig. 12, plastic strain was observed on each local surface asperity. Particularly on a part of the sliding on the die corner and that of ironing, the plastic deformation behavior of blank surface asperities was significant, because of contact with the tool surface.

By comparing the surface roughness model with the smooth surface model, the effectiveness of considering surface asperity in the model was confirmed. Two peaks of punch force maximum, which could not observed in the smooth surface

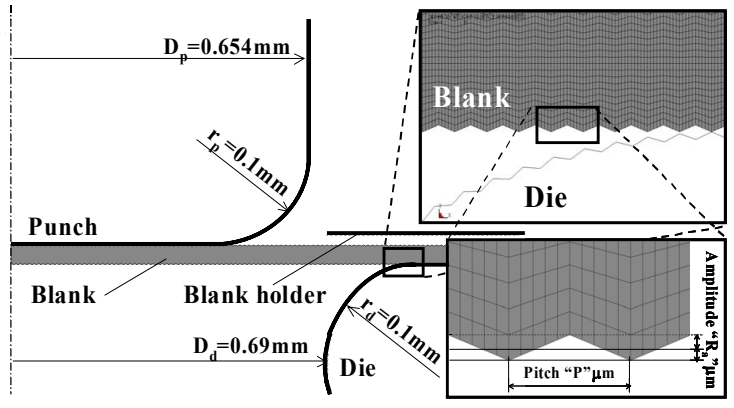

Fig. 11 Schematic illustration of the surface roughness model and tool geometry

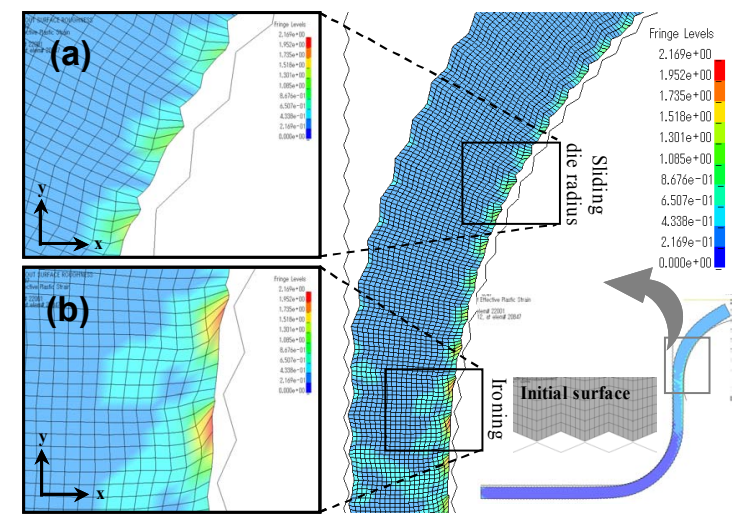

Fig. 12 Distribution of equivalent plastic strain and closeup images on part of

(a) sliding with die corner and (b) ironing

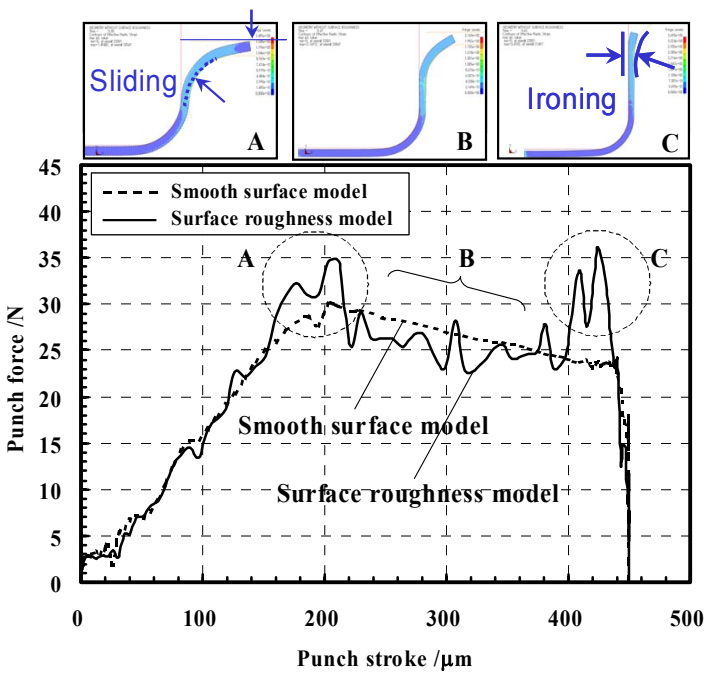

Fig. 13 Comparison between punch force-stroke curves of "surface roughness model" and "smooth surface model" model, were observed under the condition of the surface roughness model, as shown in Fig. 13. One is caused by sliding with a die corner (A) and another is caused by ironing (C). Hence, by considering the local surface asperity on the model, effect of friction resistance of each surface asperity on global forming force could be described.

Aimed to clarify the relevance between the deformations of local surface asperity and global forming behavior, the effect of geometry of local surface asperities on the drawing force was investigated by using the surface roughness model and discussed with the experimental results. 


\subsection{Simulation conditions}

Simulation was carried out with an explicit dynamic finite element code, LS-DYNA ver.970. The blank model was assumed as isotropic elastoplastic body and modeled as an $n$-th power hardening law material $\left(\sigma=K \cdot \varepsilon^{n} ; \sigma\right.$. flow stress, $K$ : strength coefficient, $\varepsilon$ : true strain, $n: \mathrm{n}$ value). Tools such as a punch, a die and a blank holder were assumed as rigid bodies. All models were considered axisymmetric. Table 3 shows the mechanical properties of the blank and tools used in the simulation, which was obtained from the tensile test of stainless steel (JIS: SUS304-H). The static and kinetic friction coefficients between the blank and the tools were assumed to be 0.05 and 0.03 , respectively.

To study the effect of combination of surface geometry between the blank and the tools on formability, different combinations of surface geometries were analyzed and evaluated with punch forces. The combination conditions of the process are given in Table 4.

Table 3 Mechanical properties used in FE analysis

\begin{tabular}{c|c|c}
\hline & Blank & Tool \\
\hline Material model & Elastic-plastic body & Rigid body \\
\hline Mass density/ $\mathrm{g} \cdot \mu \mathrm{m}^{-3}$ & $8.00 \times 10^{-9}$ & $8.00 \times 10^{-7}$ \\
\hline Young's modulus/ GPa & 177 & 206 \\
\hline Poisson's Ratio & 0.3 & - \\
\hline $\mathrm{K}$ value/ GPa & 1.55 & - \\
\hline $\mathrm{n}$ value & 0.14 &
\end{tabular}

Table 4 Combination conditions of surface geometry between blank and tools

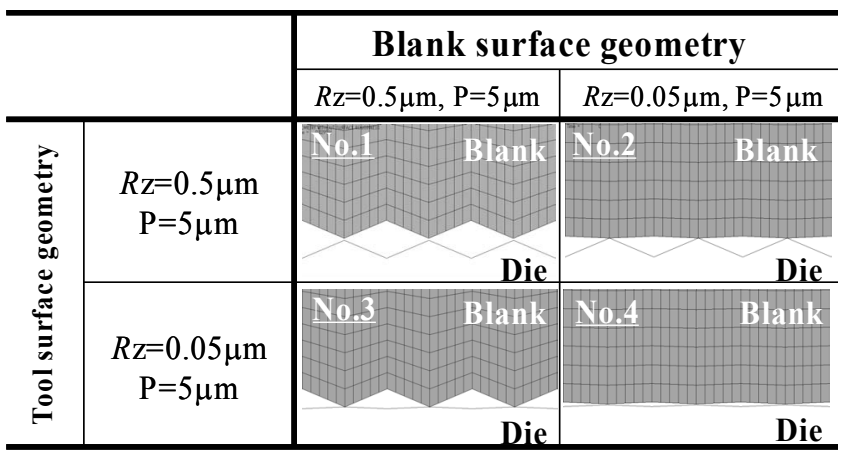

\section{Results of FE analysis and discussion}

To compare and quantify the effect of the surface topographical interaction between the tool and the material, the punch force during the process was investigated.

Figure 14 (a) shows the effect of roughness amplitude of a tool with same smooth material surface on formability (Condition No.2 and 4). The curve obtained for the rough tool indicated higher punch forces than those of smooth tool. The difference in ironing force is particularly large. This tendency was also observed in experimental results of the comparison between the untreated tool (smooth) and the air-blasted tool (rough), as shown in Fig. 7. From the history of the analysis, it can be seen that, if the tool surface asperity were sharper than the blank surface asperity, because of the intensive surface pressure, the occurrence of the plastic deformation of the blank surface asperity will be easy. Moreover, the resistance force from this plastic deformation could affect global deformation behavior. For actual contact behavior during the process, this phenomenon in FE analysis means that the oxide film layer was damaged because of the high normal pressure and adhesion or plowing occurred easily under the rough tool condition.

Figures 14 (b) and (c) show the effect of blank roughness amplitude under the same tool surface condition on punch force. For the condition with the smooth amplitude tool 
(Condition No.3 and 4) shown in Fig. 14 (b), punch force of the rough material is lower than that of the smooth material, which showed a similar tendency in the experiment shown in Fig. 10(a). It can be considered that, if the blank surface asperity is as smooth as the tool surface asperity, because the real contact area is much greater than rough amplitude blank, friction force will increase and punch force will become higher than that of the rough blank material. For the condition with a rough amplitude tool (Condition No.1 and 2) shown in Fig. 14 (c), although the maximum drawing forces are quite the same under both conditions, the higher ironing force was obtained under the condition with a smooth blank condition. In the experimental results, although the difference is not as large as that in FE analysis, a similar tendency was observed, as shown in Fig.10 (b).

As mentioned above, local interfacial behavior in micro-deep drawing could also make consideration on the basis of past experience of conventional tribological knowledge obtained in the macroscale region. However, a feature of the microscale region is that the global forming behavior is subjected much more intensely to this tribological contact behavior, which is caused by the difference of surface asperity, than that in the case of the macroscale region. Additionally, it can be said that an important factor that is predominant over the local tribological behavior is not each individual condition for surface asperity of the tool and material, but the interaction of both surface asperities that depends on the normal load condition.

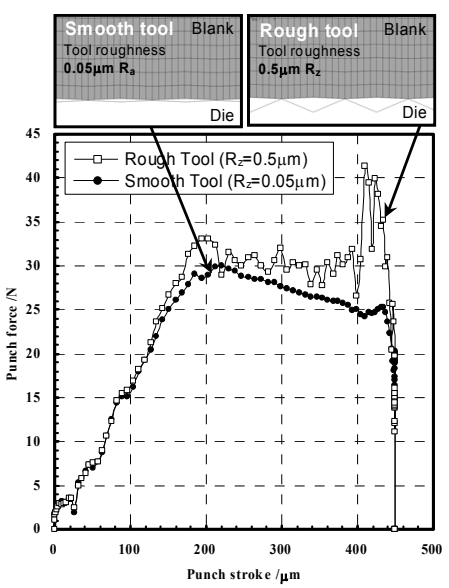

(a) Effect of tool surface amplitude

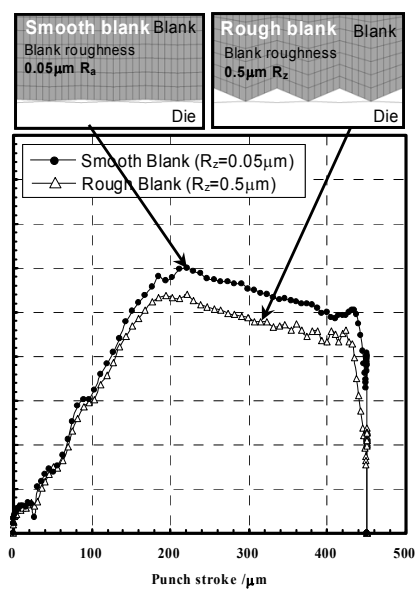

(b) Effect of blank surface amplitude with smooth tool

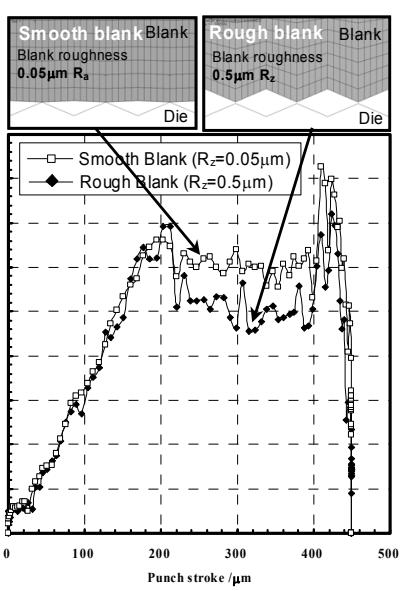

(c) Effect of blank surface amplitude with rough tool

Fig.14 FEM results of load-stroke curve under different surface conditions between tool and die

\section{Conclusion}

Aimed at clarifying the effect of increasing the relative ratio of surface roughness to outer dimensions of the tool and the material, the effect of surface asperities on formability was investigated by both experiment and FE simulation from the viewpoint of topographical interaction between the tool and the material in micro-deep drawing.

For the experimental study, micro-deep drawing for producing cups of $700 \mu \mathrm{m}$ diameter and $20 \mu \mathrm{m}$ thickness was conducted using tools and materials with different surface conditions. From the evaluation of punch force, surface accuracy and the thickness distribution of microcups, it was confirmed that "tool" surface asperities largely affect local contact behavior, so that it also affects global deformation behavior such as the formability, surface quality, and forming accuracy of the products. In addition to that, it was found that the effect of "blank" surface asperity on the formability depends on the tool surface condition. Especially under the "smooth" tool surface asperity, the influence of blank surface asperity became larger. 
Furthermore, from the investigation by FE analysis that considers surface asperities in the model, it was shown that, although local contact behavior could be explained by the conventional tribological knowledge, this local interfacial behavior of surface asperity markedly affects the global forming behavior much more in a microscale region than in a conventional macroscale region.

In other words, if the effect of the behavior would be investigated in more detail, there is some possibility of controlling deformation behavior by changing the surface asperity in the microscale region.

\section{Acknowledgement}

The authors gratefully acknowledge the support from JSPS (Japan Society for the Promotion of Science) under a JSPS Bilateral Joint Project between Japan and Russia, "A theory of surface roughness evolution at free surface and its application to mass-micro-processing design ".

\section{References}

(1) Vollertsen, F., Hu, Z., Niehoff, H.S., Theiler, C., State of the art in micro forming and investigations into micro deep drawing, Journal of Materials Processing Technology, Vol.151 (2004), pp. 70-79

(2) Engel, U., Eckstein, R., Microforming-from basic research to its realization, Journal of Materials Processing Technology, Vol.125-126 (2002), pp. 35-44

(3) Geiger, M., Messner, A., Engel, U., Production of microparts -size effect in bulk metal forming, similarity theory, Production Engineering, Vol. 4, No.1 (1997), pp. 55-58

(4) Geissdorfer, S., Engel, U., Geiger, M., FE-simulation of microforming process applying a mesoscopic model, Proceedings, 1st Intenational Conference on New Forming Technology, ICNFT (2004), pp.141-146

(5) Gau, J., Principe, C., Wang, J., An experimental study on size effects on flow stress and formability of aluminm and brass for microforming, Journal of Materials Processing Technology, Vol.184 (2007), pp. 42-46

(6) Kals, T.A., Eckstein, R., Miniaturization in sheet metal working, Journal of Materials Processing Technology, Vol.103 (2000), pp. 95-101

(7) Tiesler, N., Microforming-size effects in friction and their influence on extrusion processes, Wire, Vol. 52 (2002), pp. 34-38

(8) Engel, U., Tribology in microforming, Wear, Vol.260 (2006), pp. 265-273

(9) Hu, Z., Vollertsen, F., Tribological size effect in sheet metal forming, Proceedings, International Conference on Tribology in Manufacturing Processes, ICTMP 2007, (2007), CD-ROM

(10) Nosonovsky, M., Bhushan, B., Scale effect in dry friction during multiple-asperity contact, Journal of Tribology, Vol. 127, No.1 (2005), pp. 37-36

(11) Manabe, K., Shimizu, T., Koyama, H., Yang, M., Ito, K., Validation of FE simulation based on surface roughness model in micro-deep drawing process, Journal of Materials Processing Technology, Vol.204 (2008), pp. 89-93

(12) Yang, M., Manabe, K., Ito, K., Micro press forming and assembling of micro parts in a progressive die, Proceedings, 10th Advances in Materials and Processing Technologies, AMPT (2007), pp. 495-503

(13) Yang, M., Osako, A., Application of ion irradiation for surface finish of micro forming die, Proceedings, 10th Advances in Materials and Processing Technologies, AMPT (2007), pp. 737-742 